\title{
Tracheal Injury Caused by Self-stabbing over the Low Anterior Neck
}

\author{
Chan Yong Park', Hyun Min Cho', Seok Ran Yeom ${ }^{2}$ \\ ${ }^{1}$ Department of Trauma Surgery, Pusan National University Hospital, Busan, Korea \\ ${ }^{2}$ Department of Emergency Medicine, Pusan National University Hospital, Busan, Korea
}

We report on a 36-year-old man who presented to the emergency department with a self-inflicted neck stab injury. Initial vital signs were stable. Arterial blood test revealed $\mathrm{pH} 7.41, \mathrm{pCO}_{2} 38 \mathrm{mmHg}, \mathrm{pO}_{2} 71 \mathrm{mmHg}$, and $\mathrm{SaO}_{2}$ 94\%. On physical examination, a $10 \mathrm{~cm}$ length transverse laceration with a skin defect in the lower anterior neck was observed. Computed tomography (CT) angiography showed a soft skin defect in the anterior neck at Zone I, subcutaneous emphysema at the anterior neck and chest wall, and pneumomediastinum. Emergency operative findings showed a penetrating tract in the direction of the trachea just above the suprasternal notch in the laceration wound. A $1.5 \mathrm{~cm}$ laceration of the tracheal membrane was observed between tracheal rings 4 and 5 . The tracheal rings were repaired by absorbable sutures. The patient was discharged without any complications.

(Trauma Image Proced 2017(1):35-39)

Key Words: Trachea injuries; Neck injuries; Mediastinal emphysema; Trachea

\section{CASE}

A 36-year-old man presented to the emergency department with a self-inflicted neck stab injury. His vital signs were blood pressure $110 / 70 \mathrm{mmHg}$, pulse rate 112 beats/min, respiration rate 20 breaths/min, body temperature $36.2^{\circ} \mathrm{C}$, and oxygen saturation 97\%. Laboratory examination revealed $\mathrm{pH} 7.41, \mathrm{pCO}_{2} 38 \mathrm{mmHg}$, $\mathrm{pO}_{2} 71 \mathrm{mmHg}, \mathrm{SaO}_{2} 94 \%$, white blood cell count 22.0 x $10^{3} / \mu \mathrm{L}$, hemoglobin $14.1 \mathrm{~g} / \mathrm{dL}$, platelet $356 \times 10^{3}$ /aL, lactic acid $2.5 \mathrm{mmol} / \mathrm{L}$, and base excess -0.3. A $10-\mathrm{cm}$ transverse laceration with a skin defect in the lower anterior neck was observed on physical examination. Neck computed tomography (CT) angiography showed a soft skin defect in the anterior neck of Zone I, subcutaneous emphysema at the anterior neck and chest wall, and pneumomediastinum. An endotracheal intubation was performed in the emergency department. An emergency operation was performed under suspicion of tracheal injury. Operative findings showed a penetrating tract in the direction of the trachea just above the suprasternal notch in the laceration wound. A $1.5 \mathrm{~cm}$ laceration was observed in the membrane between $4^{\text {th }}$ and $5^{\text {th }}$ tracheal rings, and a balloon of endotracheal tube was observed through the defect of the trachea. After gentle repositioning of the endotracheal tube to the proximal site from the tracheal defect, the tracheal defect was repaired by absorbable sutures. Extubation was

Received: February 15, 2017 Revised: March 1, 2017 Accepted: March 7, 2017

Correspondence to: Chan Yong Park, Department of Trauma Surgery, Pusan National University Hospital, 179, Gudeok-ro, Seo-gu, Busan 49241, Korea

Tel: 82-51-240-7369, Fax: 82-51-240-7719, E-mail: wkafyddl@hanmail.net

Copyright (c) 2017 Korean Association for Research, Procedures and Education on Trauma. All rights reserved.

@) This is an open-access article distributed under the terms of the Creative Commons Attribution Non-Commercial License (http://creativecommons.org/ licenses/by-nc/4.0) which permits unrestricted noncommercial use, distribution, and reproduction in any medium, provided the original work is properly cited 


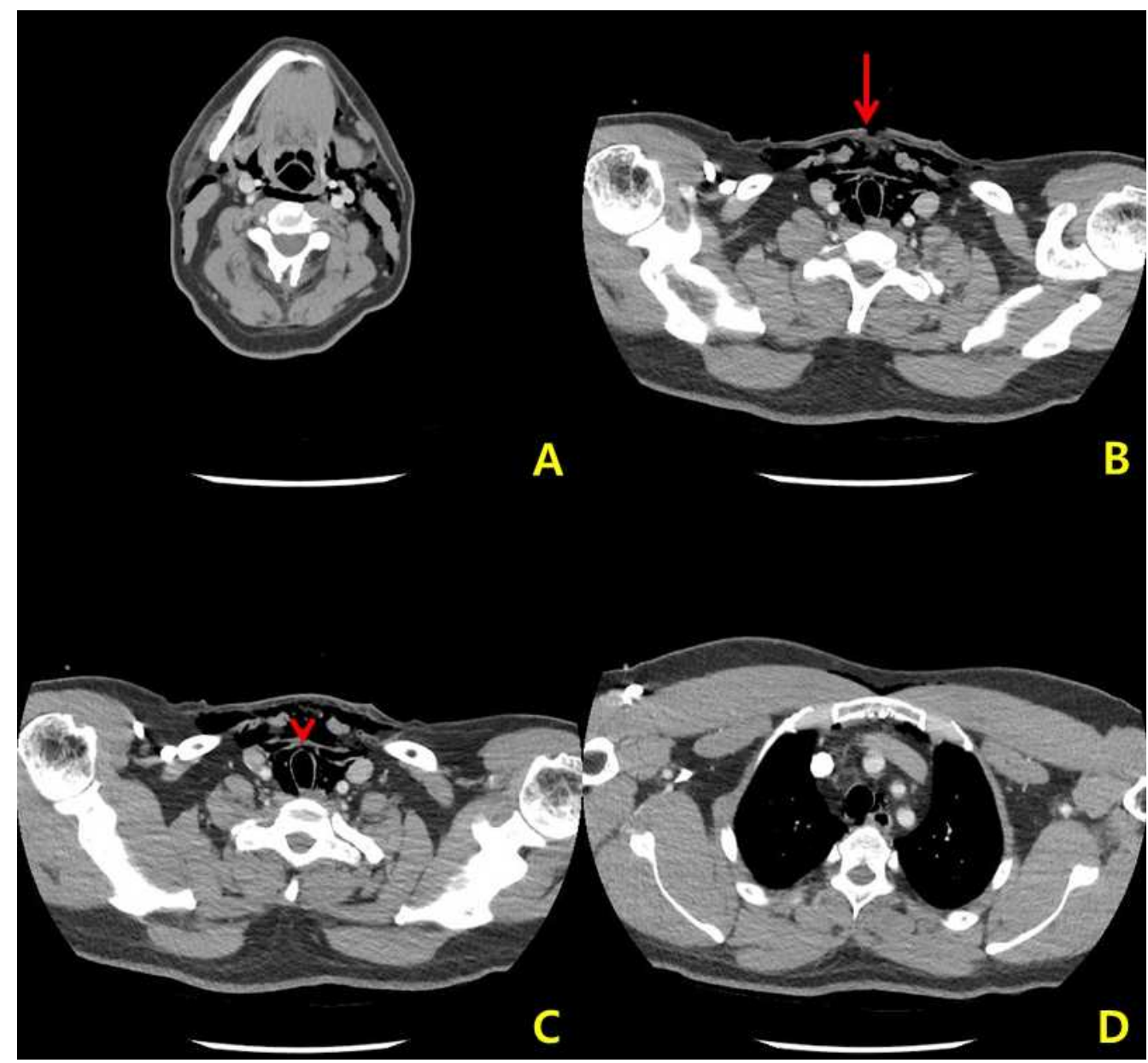

Fig. 1. Neck CT demonstrates subcutaneous and mediastinal emphysema. (A) Emphysema on the upper neck. (B) Penetrating focus on the neck (red arrow). (C) Suspicious disruption point of continuity of trachea (red arrowhead). (D) Pneumomediastinum.

performed in the operating room after the operation. At a bronchoscopy performed on postoperative day 3 , the repaired defect of the trachea was intact and there was no any other abnormality. Neck CT on postoperative day 5 showed no subcutaneous and mediastinal emphysema. The patient was discharged without any complications.

\section{DISCUSSION}

Bronchial injuries are relatively rare but often fatal. Huh et al. (1) reported a $0.13 \%$ incidence of bronchotracheal injury in their university level I trauma center. For successful management of penetrating neck injuries, aggressive initial airway management, high index of suspicion, accurate diagnosis of tracheobronchial injury, and the appropriate repair in the early stage are essential (1-7). Multidetector CT (MDCT) and bronchoscopy before or during surgery are helpful for diagnosis $(7,8)$. Inaba et al. (9) reported that multi slice helical CT angiography (MCTA) appears to be a sensitive and safe screening modality. MCTA achieved $100 \%$ sensitivity and $93.5 \%$ sensitivity in detecting all vascular and aerodigestive injuries sustained. The indications for surgery in cases of penetrating neck trauma included increased subcutaneous emphysema, bleeding from the wound, and mediastinal hematoma (4). Modern operative approaches have significantly decreased the incidence of complications in the past, such as wound infections, tracheal stenosis, splitting of sutures, and tracheoesophageal fistulas. These operative approaches for penetrating 


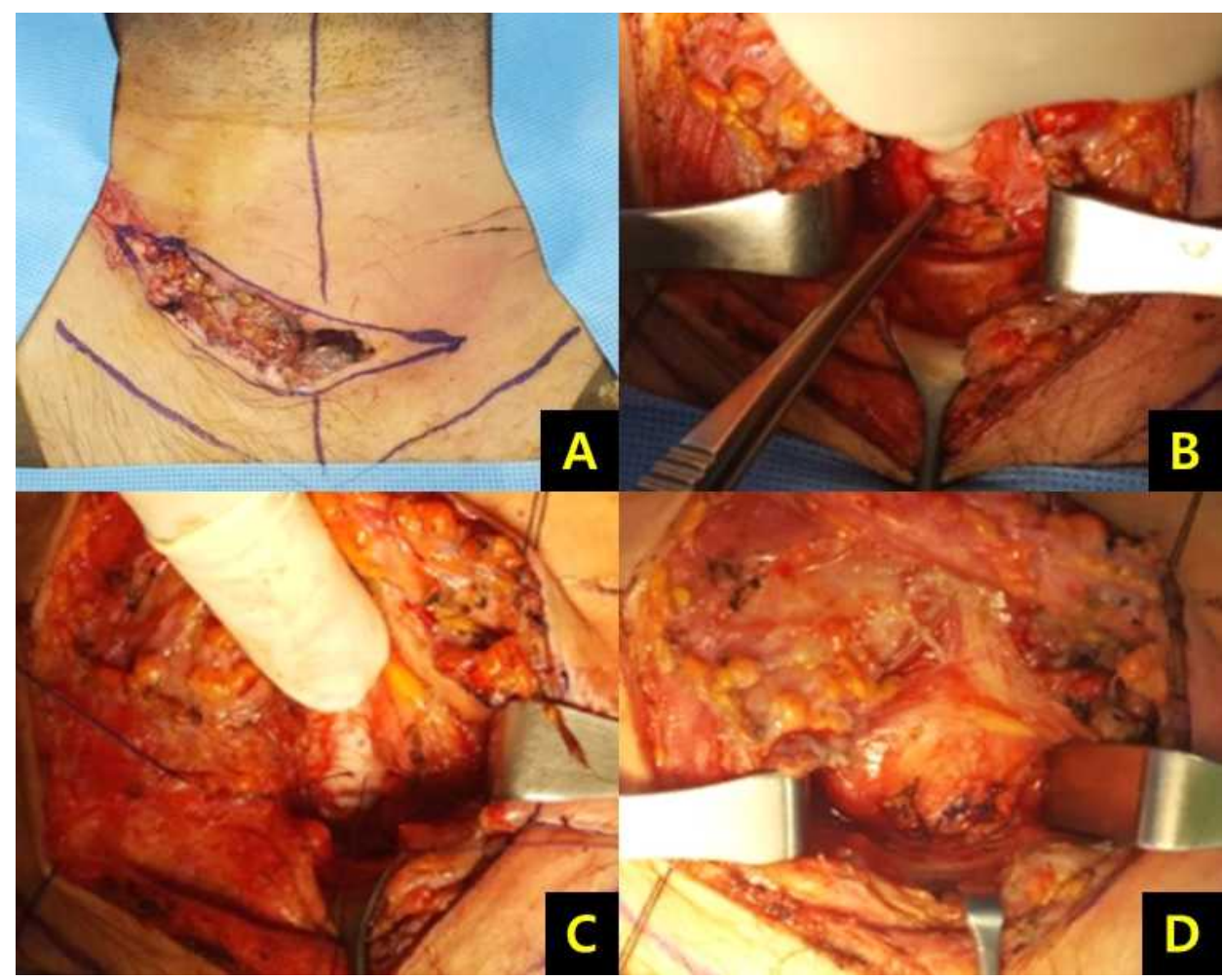

Fig. 2. Operative findings show tracheal injury just above the suprasternal notch. (A) A $10-\mathrm{cm}$ laceration with skin defect on low anterior neck. (B) A 1.5- $\mathrm{cm}$ sized laceration in the membrane between 4th and 5th tracheal rings, and a balloon of endotracheal tube was observed inside the trachea. (C) After gentle repositioning of the endotracheal tube to the proximal site from the tracheal defect, the tracheal defect was repaired by absorbable sutures. (D) Features after simple repair for the tracheal defect.

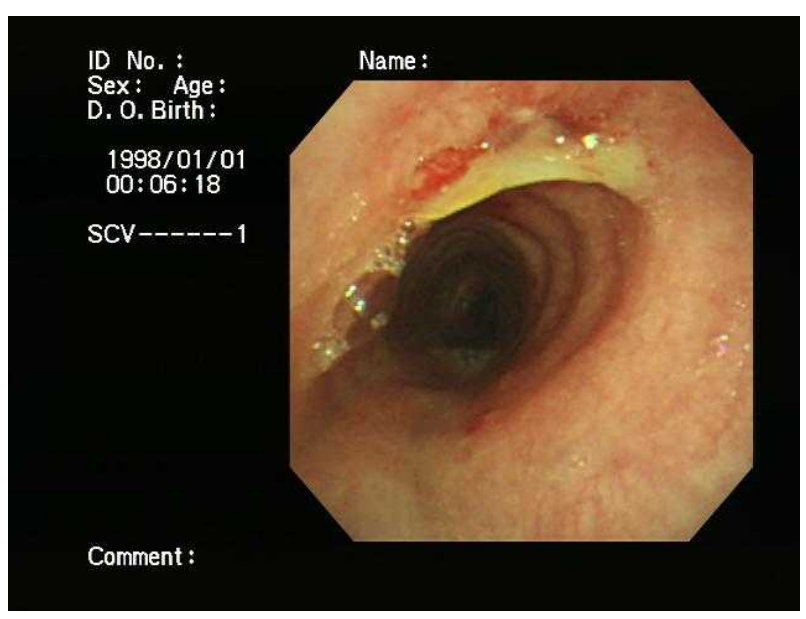

Fig. 3. A bronchoscopy performed on postoperative day 3 shows the repaired defect of the trachea is intact.

tracheal injuries included the following conditions: 1) an emphasis on clinical recognition of injury, 2) minimal peritracheal dissection and repair with absorbable sutures, 3) limited use of protective tracheostomies, and 4) use of muscle buttresses to cover tracheal repairs (10). Simple repair can be performed safely for airway injuries with good results (3). In this case, simple repair was performed using 3-0 Vicryl. Togashi et al. (6) reported that controlled ventilation was required under heavy sedation for more than 1 week after end-to-end anastomosis if the trachea was completely disrupted.

\section{Conflict of Interest Statement}

This work was supported by clinical research grant from Pusan National University Hospital in 2015. 


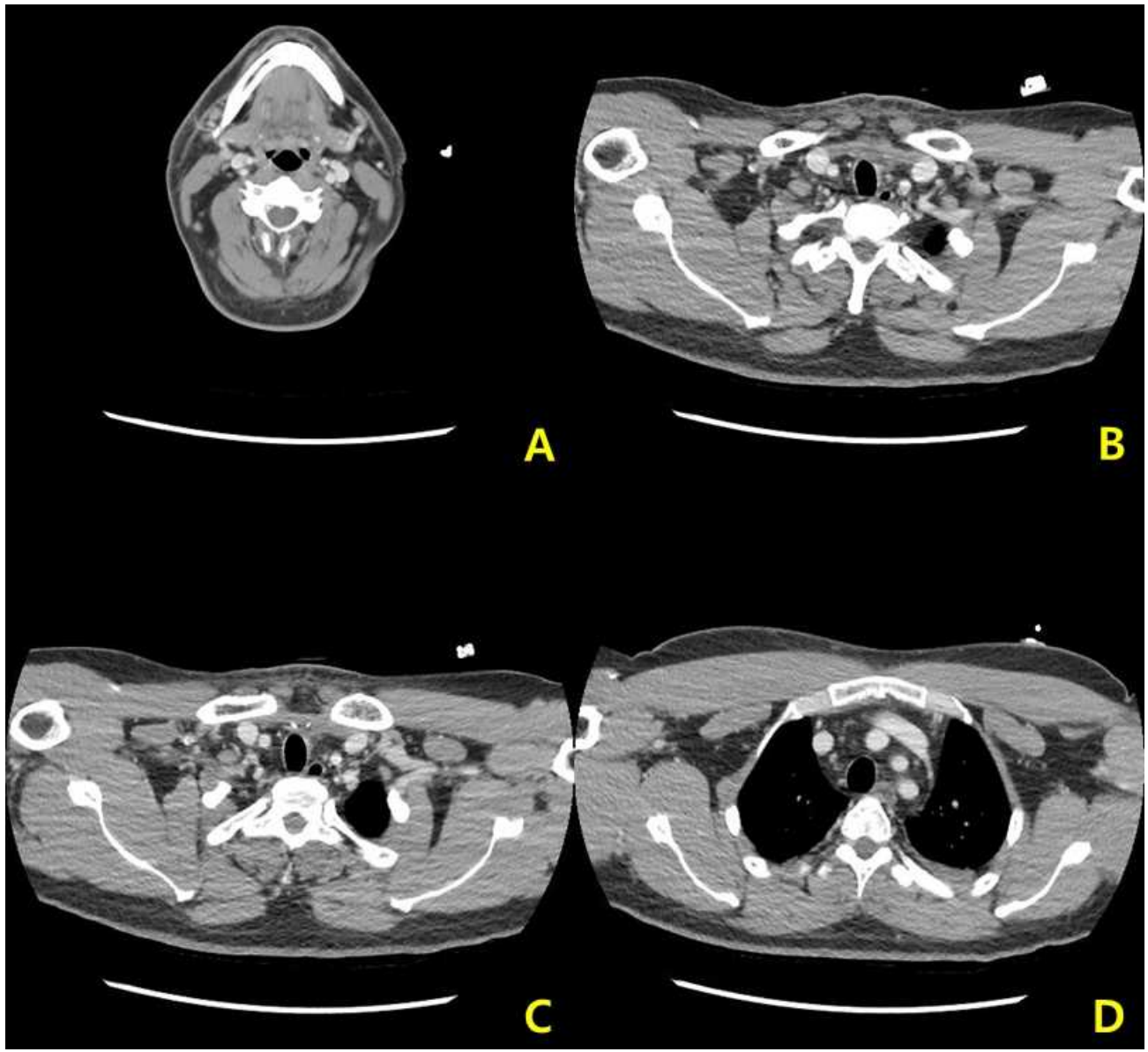

Fig. 4. Neck CT on postoperative day 5 shows resolution of the subcutaneous and mediastinal emphysema. The patient was discharged without any complications.

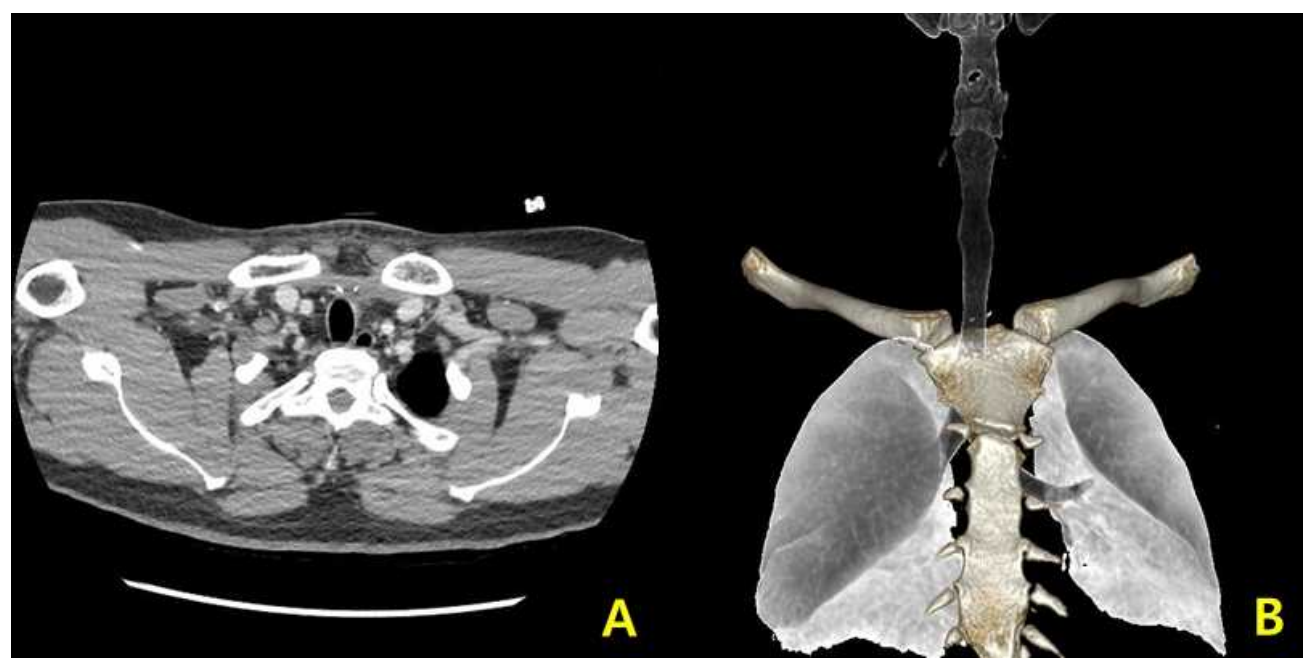

Fig. 5. Two clips indicating the level of tracheal injury are observed on postoperative neck CT. 


\section{REFERENCES}

1. Huh J, Milliken JC, Chen JC. Management of tracheobronchial injuries following blunt and penetrating trauma. The American surgeon. 1997;63(10):896-9.

2. Edwards Jr W, Morris Jr J, DeLozier 3rd J, Adkins Jr R. Airway injuries. The first priority in trauma. The American surgeon. 1987;53(4):192-7.

3. Grewal H, Rao PM, Mukerji S, Ivatury RR. Management of penetrating laryngotracheal injuries. Head \& neck. 1995;17(6):494-502.

4. Łochowski M, Kaczmarski J, Brzeziński D, Cieślik-Wolski B, Kozak J. Penetrating neck traumas. Kardiochirurgia i Torakochirurgia Polska. 2014;11(1):30-3.

5. Shimizu T, Matsuzaki Y, Onitsuka T. Surgical treatment for traumatic tracheobronchial injuries. Kyobu geka The Japanese journal of thoracic surgery. 2006;59(11):1007-11.

6. Togashi $\mathrm{K}-\mathrm{i}$, Sugawara $\mathrm{M}$, Sato $\mathrm{Y}$, Miyamura $\mathrm{H}$.
Successful surgical management of complete tracheal disruption due to penetrating injury. The Japanese Journal of Thoracic and Cardiovascular Surgery. 2002;50(5):213-5.

7. Vodicka J, Spidlen V, Klecka J, Vacek V, Simanek V, Safranek J. Tracheobronchial injuries--experience with diagnosis and therapy. Rozhledy v chirurgii: mesicnik Ceskoslovenske chirurgicke spolecnosti. 2003;82(4):199-204.

8. Soliman A, Ahmad SM, Roy D. The role of aerodigestive tract endoscopy in penetrating neck trauma. The Laryngoscope. 2014;124(S7):S1-S9.

9. Inaba K, Munera F, McKenney M, Rivas L, De Moya M, Bahouth $\mathrm{H}$, et al. Prospective evaluation of screening multislice helical computed tomographic angiography in the initial evaluation of penetrating neck injuries. Journal of Trauma and Acute Care Surgery. 2006;61(1):144-9.

10. Lyons JD, Feliciano DV, Wyrzykowski AD, Rozycki GS. Modern management of penetrating tracheal injuries. The American Surgeon. 2013;79(2):188-93. 